\title{
SISTEM INFORMASI ADMINISTRASI PEMBAYARAN SDS MUHAMMADIYAH 06 TEBET TIMUR
}

\author{
Mardiana $^{1}$, Nunu Kustian ${ }^{2}$, Ek Ajeng Rahmi Pinahayu ${ }^{3}$ \\ Program Studi Teknik Informatika, Fakultas Teknik dan Ilmu Komputer, \\ Universitas Indraprasta PGRI \\ Jalan Raya Tengah No 80, Kelurahan Gedong, Pasar Rebo, Jakarta Timur \\ mardiana.ana16@gmail.com ${ }^{1}$, kustiannunu@gmail.com ${ }^{2}$, ekajeng_rahmipinahayu@yahoo.com ${ }^{3}$
}

\begin{abstract}
Abstrak
Komputer merupakan salah satu alat atau media yang digunakan untuk mengolah data administrasi yang ada. Salah satunya yaitu data administrasi pembayaran sekolah, sehingga semua pihak yang memerlukan akan lebih mudah mengakses data administrasi pembayaran sekolah dengan cepat dan akurat. Salah satu sistem informasi yang sangat dibutuhkan oleh suatu instansi pendidikan yaitu mengenai pembayaran sekolah. Rumusan masalah ini antara lain bagaimana membuat sistem administrasi pembayaran tidak membutuhkan yang lama dan mempermudah pegawai dalam melakukan pembuatan laporan data pembayaran. Penelitian ini bertujuan untuk membuat sistem informasi administrasi pembayaran SDS Muhammadiyah 06 Tebet Timur yang bisa mengolah data pembayaran, memberikan bukti pembayaran, serta memiliki fitur pencarian data siswa dan data pembayaran siswa. Metode penelitian yang digunakan dengan melakukan observasi pada sekolah SDS Muhammadiyah 06 Tebet Timur untuk mengamati dan mempelajari secara langsung mengenai proses pengolahan data administrasi pembayaran sekolah, dan juga melakukan wawancara dengan pegawai Tata Usaha dengan hasil mendapatkan data mengenai administrasi pembayaran yang sedang berjalan. Hasil penelitian menunjukkan bahwa sistem informasi administrasi pembayaran selama ini masih menggunakan proses pembayaran secara konvensional kini menjadi secara komputerisasi karena data-data tersebut tersimpan di dalam database.
\end{abstract}

Kata Kunci: Administrasi, Pembayaran, Sistem Informasi

\begin{abstract}
Computers are one of the tools or media used to process existing administrative data. One of them is school payment administration data, so that all parties who need it will more easily access school payment administration data quickly and accurately. One of the information systems needed by an educational institution is about school payments. The formulation of this problem, among others, is how to make the payment administration system take less time and make it easier for employees to make payment data reports. This study aims to create a payment administration information system for SDS Muhammadiyah 06 Tebet Timur that can process payment data, provide proof of payment, and have student data search and student payment data features. The research method used by observing the school SDS Muhammadiyah 06 Tebet Timur to observe and learn directly about the process of processing school payment administration data, and also conducting interviews with administrative staff with the results of obtaining data about ongoing payment administration. The results showed that the payment administration information system has been using the conventional payment process and is now computerized because the data is stored in the database.
\end{abstract}

Keyword: Administration, Information Systems, Payment

\section{PENDAHULUAN}

Teknologi informasi adalah bagian dari sistem informasi dan teknologi informasi merujuk pada teknologi yang digunakan dalam menyampaikan maupun mengolah informasi. Perkembangan teknologi informasi saat ini semakin berkembang dengan cepat, seiring meningkatnya populasi manusia akan kebutuhan teknologi dan informasi. Tanpa membuang banyak waktu, tenaga dan biaya maka informasi yang diperlukan oleh manusia akan cepat didapatkan dengan berkembangnya teknologi. Salah satu sistem informasi yang sangat dibutuhkan oleh suatu instansi pendidikan yaitu mengenai pembayaran sekolah. Sistem informasi pembayaran sekolah tersebut, yang tadinya dicatat secara konvensional kini dilakukan secara komputerisasi untuk mempermudah bagian tata usaha dalam melakukan pengecekan masalah data pembayaran sekolah siswa dan petugas tidak akan mengalami kesulitan dalam melakuan pencarian data pembayaran. Sehingga dibutuhkannya sebuah apikasi yang dapat mengatasi permasalahan tersebut menjadi lebih baik. 
Menurut (Mulyadi, 2016) sistem adalah suatu jaringan prosedur yang dibuat menurut pola yang terpadu untuk melaksanakan kegiatan pokok perusahaan. Menurut (Hutahaean, 2015) sistem adalah suatu jaringan kerja dari prosedur-prosedur yang saling berhubungan, berkumpul bersamasama untuk melakukan kegiatan atau untuk melakukan sasaran yang tertentu. Jadi dari beberapa pengertian sistem menurut para ahli, kita akan mengambil pengertian bahwa sistem adalah suatu jaringan kerja yang saling berhubungan satu sama lain untuk melaksanakan kegiatan pokok perusahaan secara bersama-sama dalam mencapai tujuan tertentu.

Menurut (Romney, M. B., \& Steinbart, 2015) informasi (information) adalah data yang telah dikelola dan diproses untuk memberikan arti dan memperbaiki proses pengambilan keputusan. Sebagaimana perannya, pengguna membuat keputusan yang lebih baik sebagai kuantitas dan kualitas dari peningkatan informasi. Berdasarkan pengertian tersebut dapat disimpulkan bahwa pengertian informasi adalah hasil kegiatan pengolahan data yang memberikan bentuk lebih berarti dari suau kejadian dalam membuat keputusan yang lebih baik bagi penggunanya. Sistem informasi, yang kadang kala disebut sebagai sistem pemrosesan data, merupakan sistem buatan manusia yang biasanya terdiri dari sekumpulan komponen (baik manual maupun berbasis komputer) yang terintegrasi untuk mengumpulkan, menyimpan, dan mengelola data serta menyediakan informasi mengenai saldo persediaan (Anastasia, D., \& Lilis, 2011). Jadi dari pengertian sistem informasi menurut para ahli tersebut, kita akan mengambil pengertian bahwa sistem informasi adalah sebuah data yang dikelompokkan oleh seseorang yang terdiri dari sekumpulan komponen yang terintegrasi dan menghasilkan output yang berguna bagi pemakai dalam pengambilan keputusan.

Menurut Dewi (2011: 3), administrasi merupakan proses kerjasama beberapa individu dengan cara yang efisien dalam mencapai tujuan sebelumnya. Menurut (Handayani, 2015) pembayaran adalah suatu tindakan menukarkan sesuatu (uang/barang) dengan maksud dan tujuan yang sama yang dilakukan oleh dua orang atau lebih. Menurut Hasibuan (Hasibuan, 2010) pembayaran adalah berpindahnya hak pemilikan atas sejumlah uang atau dan dari pembayar kepada penerimanya, baik langsung maupun melalui media jasa-jasa perbankan. Jadi dari pengertian pembayaran menurut para ahli tersebut, pembayaran adalah suatu tindakan menukarkan sesuatu berupa uang/barang dari pembayar kepada penerimanya dengan maksud dan tujuan yang sama, baik langsung maupun melalui media jasa-jasa perbankan. Menurut (Komariah, A., \& Triatna, 2010) sekolah merupakan suatu sistem yang kompleks karena selain terdiri atas input-proses-output juga memiliki akuntabilitas terhadap konteks pendidikan dan outcome. Jadi dari pengertian menurut para ahli tersebut sekolah adalah suatu sistem atau salah satu agen sosialisasi yang kompleks dalam kehidupan manusia dan memiliki akuntabilitas terhadap konteks pendidikan.

Rumusan masalah dalam penelitian ini adalah adalah bagaimana membuat sistem agar dalam pengolahan data pembayaran tidak membutuhkan waktu yang lama dan dapat mempermudah pegawai dalam melakukan pengolahan data siswa maupun dalam pembuatan laporan data pembayaran. Manfaat hasil penelitian ini yaitu terciptanya sebuah sistem administrasi pembayaran sekolah yang dapat membantu kinerja bagian tata usaha khususnya bagian keuangan siswa.

\section{PENELITIAN RELEVAN}

Penelitian oleh (Hanif, 2016) yang berjudul Sistem Informasi Administrasi Pembayaran pada SDIT Al Akhyar Kudus dari Universitas Muara Kudus tahun 2016. Sistem pembayaran yang dilakukan oleh SDIT Al Akhyar Kudus masih menggunakan metode manual yang mengakibatkan kesalahan akuntansi dalam laporan keuangan proses sekolah dilakukan oleh administrator sekolah. Informasi yang akurat diperlukan untuk mengantisipasi kesalahan yang terjadi. Hasil penelitian tersebut ialah diharapkan mampu membuat sistem informasi yang dapat digunakan untuk proses pengelolaan administrasi pembayaran pada SDIT Al Akhyar Kudus.

Penelitian (Prabowo, 2015) yang berjudul Rancang Bangun Sistem Administrasi Pembayaran Sekolah Multi User Berbasis Web Di SMA Negeri 1 Temanggung tahun 2015. Hasil penelitian ini adalah sistem informasi yang dibangun dapat menjalankan proses administrasi pembayaran sekolah dimulai dari pengelolaan dan pelaporan data kelas, siswa, guru, tahun ajaran, serta data lain yang diperlukan lalu melakukan administrasi pembayaran yang meliputi pembayaran uang SPP dan uang pembangunan. Selain itu, sistem informasi yang telah terkomputerisasi dapat diakses oleh 
admin, siswa, guru BK (Bimbingan Konseling), Petugas Tata Usaha, Wali Kelas. Sistem yang telah divalidasi oleh beberapa ahli, sehingga sudah dapat dikatakan bahwa sistem telah layak untuk diimplementasikan.

\section{METODE PENELITIAN}

\section{Observasi}

Peneliti melihat secara langsung mengenai objek dan penelitian yang sedang diamati.

\section{Wawancara}

Dimana peneliti melakukan wawancara dengan pegawai tata usaha di SDS Muhammadiyah 06 untuk melakukan pengumpulan data mengenai administrasi pembayaran SDS Muhammadiyah 06. Ada beberapa hal yang dibahas dalam wawancara ini yaitu mulai dari proses data siswa hingga proses pembayarannya.

\section{Langkah-langkah Pengembangan Sistem}

Model pengembangan sistem yang dilakukan dalam membangun aplikasi administrasi pembayaran sekolah yaitu menggunakan model air terjun (waterfall). Menurut (Sukamto, R. A., \& Shalahuddin, 2013) "Model air terjun menyediakan pendekatan alur hidup perangkat lunak secara sekuensial atau terurut dimulai dari analisis, desain pengodean, pengujian dan tahap pendukung (support)". Langkah-langkah pengembangan sistem yang dibutuhkan untuk merancang sebuah sistem secara rinci, yaitu sebagai berikut:

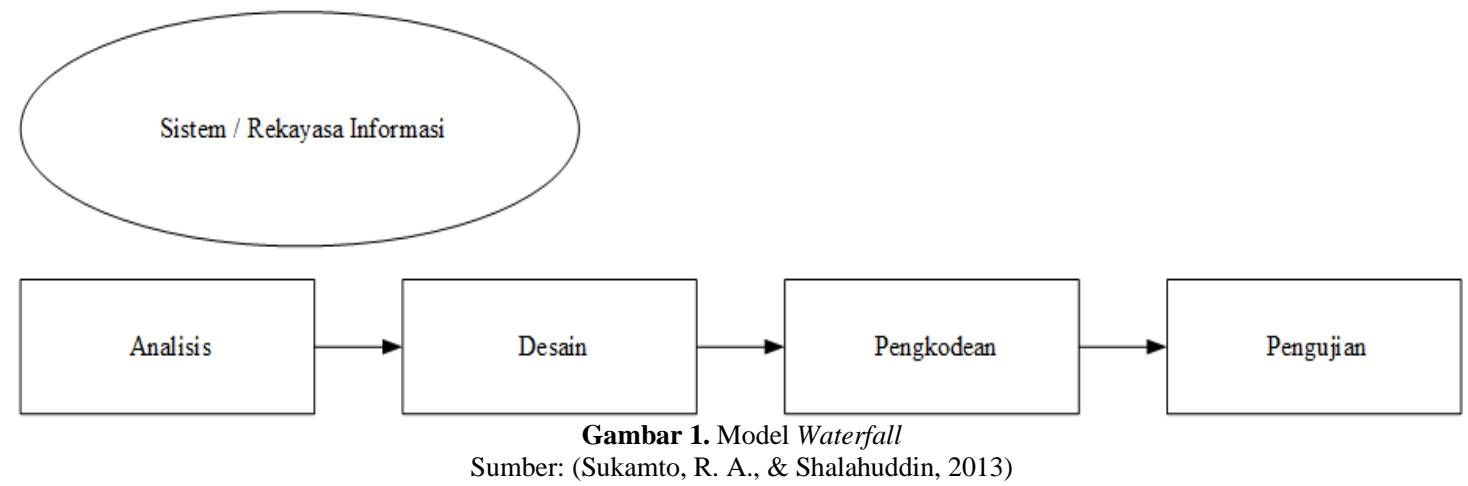

\section{Analisis Kebutuhan Perangkat Lunak}

Dalam tahap ini, peneliti melakukan proses pengumpulan kebutuhan secara intensif agar dapat dipahami untuk menspesifikasikan kebutuhan perangkat lunak apa yang dibutuhkan oleh administrasi pembayaran SDS Muhammadiyah 06 Tebet Timur.

\section{Desain}

Dalam tahap ini, peneliti melakukan pembuatan desain perangkat lunak dengan menggunakan java untuk merancang tampilan layar pada sistem informasi administrasi pembayaran SDS Muhammadiyah 06 Tebet Timur. Agar dapat diimplementasikan menjadi program pada tahap selanjutnya.

\section{Pembuatan Kode Program}

Pada tahap ini, peneliti membuat kode program pada aplikasi administrasi pembayaran SDS Muhammadiyah 06 Tebet Timur dengan desain yang sudah ditranslasikan ke dalam program perangkat lunak. Hasil pada tahap ini adalah program komputer sesuai dengan desain yang sudah dibuat pada tahap desain.

\section{Pengujian}

Pada tahap ini, peneliti melakukan pengujian terhadap aplikasi administrasi pembayaran SDS Muhammadiyah 06 Tebet Timur dengan menggunakan pengujian black box testing dimana pengujian tersebut menekankan pada fungsionalitas yang ada dari setiap bagian di dalam sistem yang dibuat tanpa mengetahui bait program yang ada dengan tujuan untuk memastikan setiap bagian sudah sesuai dengan alur proses yang ditetapkan. Hal ini dilakukan untuk meminimalisir 
kesalahan masukan yang dilakukan oleh pengguna dapat ditangani oleh sistem dan memastikan keluaran yang dihasilkan sesuai dengan yang diinginkan.

\section{HASIL DAN PEMBAHASAN}

\section{Analisa Permasalahan}

Sistem informasi administrasi pembayaran pada SDS Muhammadiyah 06 Tebet Timur belum efektif karena belum ada sistem yang terkomputerisasi. Bagian Tata Usaha merasa kesulitan dalam melakukan pencarian data siswa yang dibutuhkan karena proses masih menggunakan cara manual, sehingga terjadinya kesalahan dalam pengolahan data siswa maupun pencatatan pembayaran siswa. Dalam pembuatan laporan data pembayaran siswa belum ada bentuk laporan yang dilakukan secara komputerisasi. Hal ini mendorong peneliti untuk mencoba mengembangkan rancangan sistem informasi administrasi pembayaran pada SDS Muhammadiyah 06 Tebet Timur.

\section{Diagram Konteks Sistem yang Diusulkan}

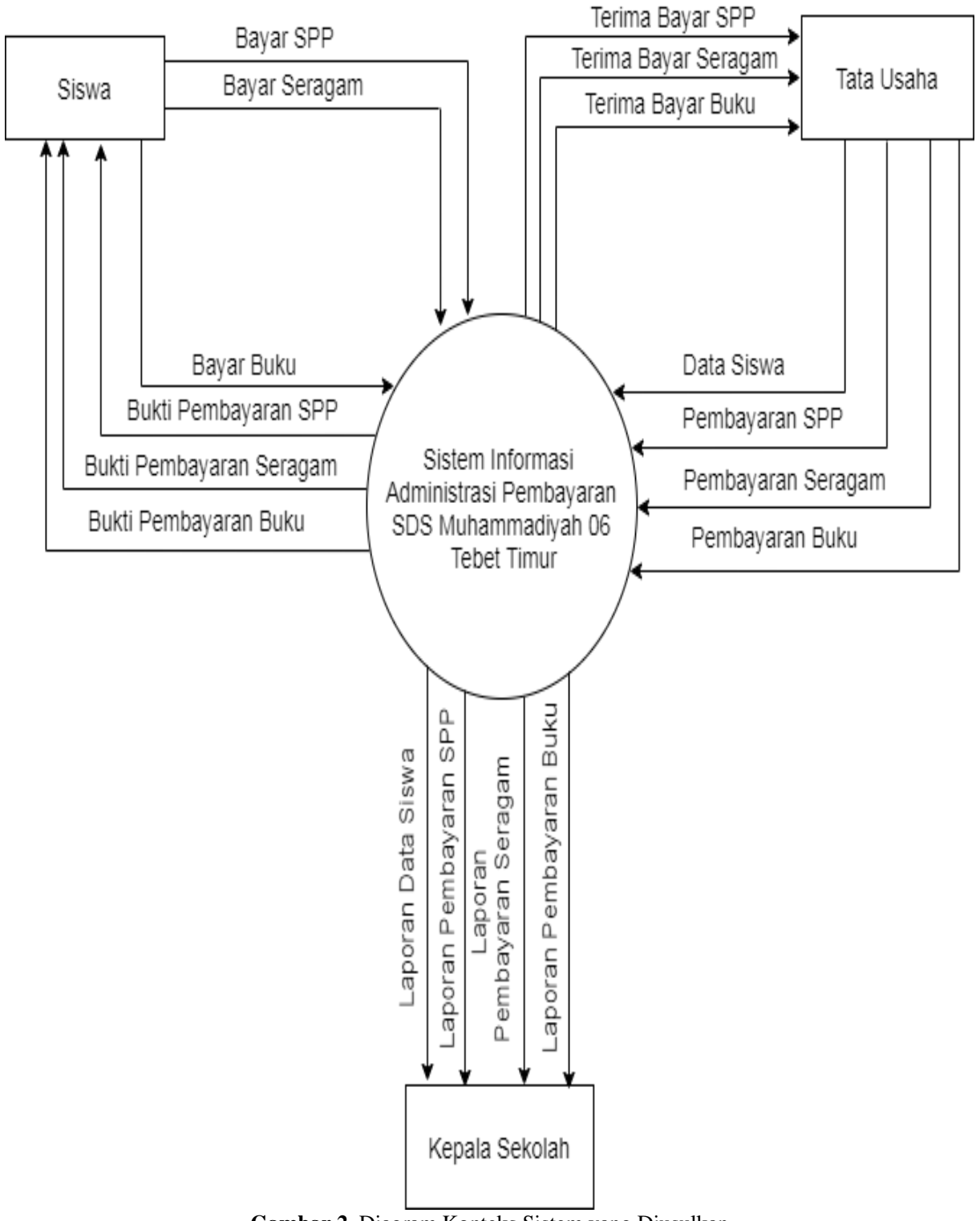

Gambar 2. Diagram Konteks Sistem yang Diusulkan 


\section{Entity Relationship Diagram (ERD)}

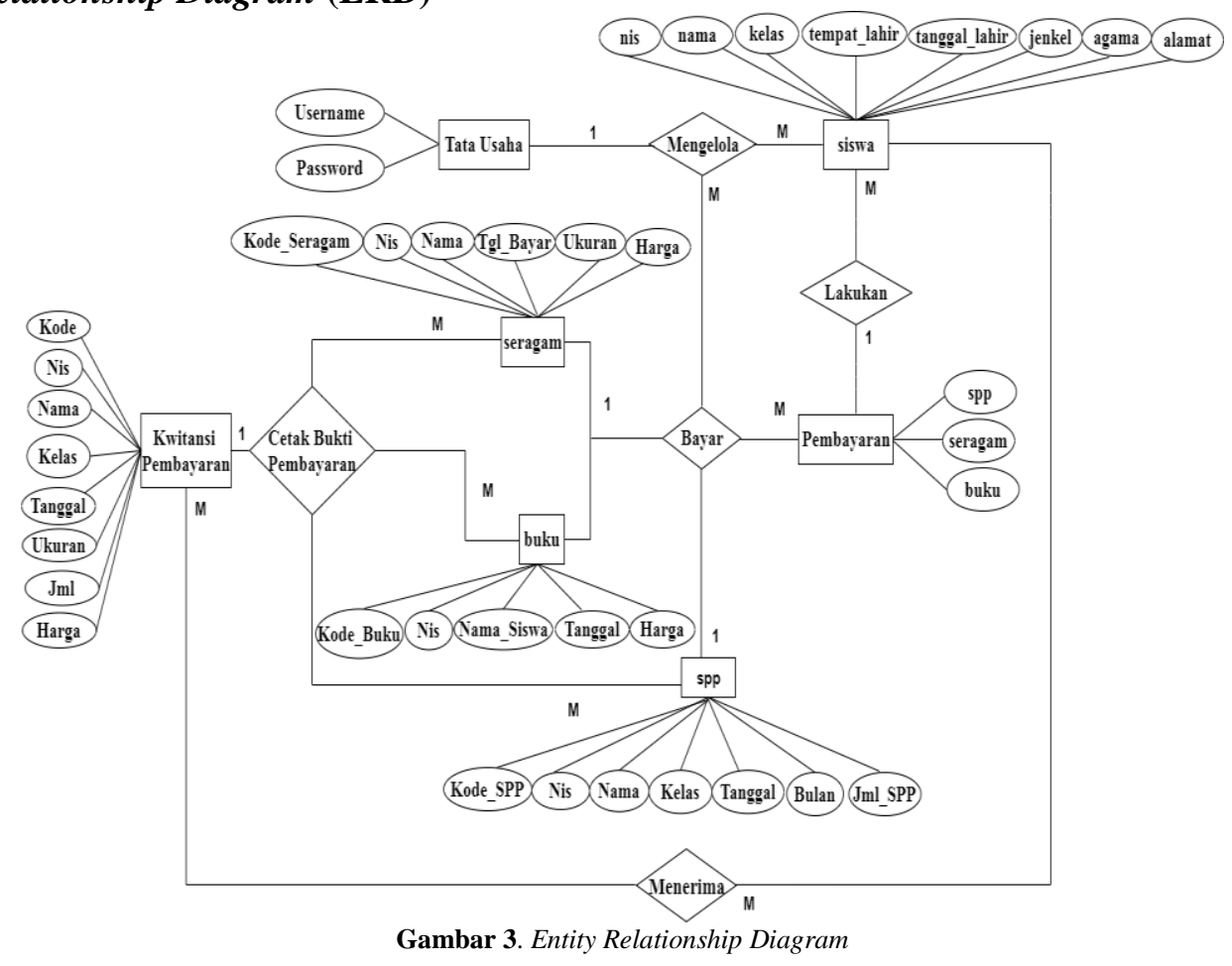

\section{Tampilan}

Berikut ini adalah tampilan hasil perancangan sistem informasi administrasi pembayaran SDS 06 Tebet Timur.

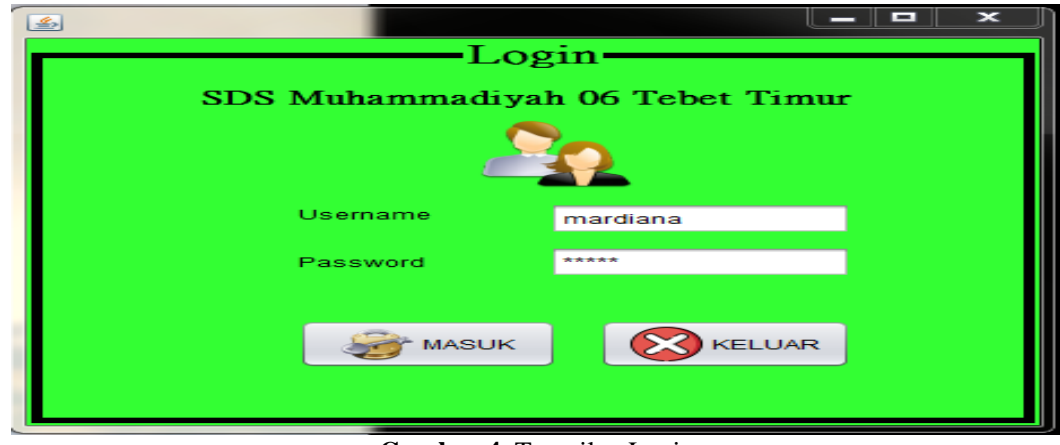

Gambar 4. Tampilan Login

Layar di atas akan muncul di awal saat pengoperasian program. Halaman login diisi oleh petugas tata usaha sebagai administrator.

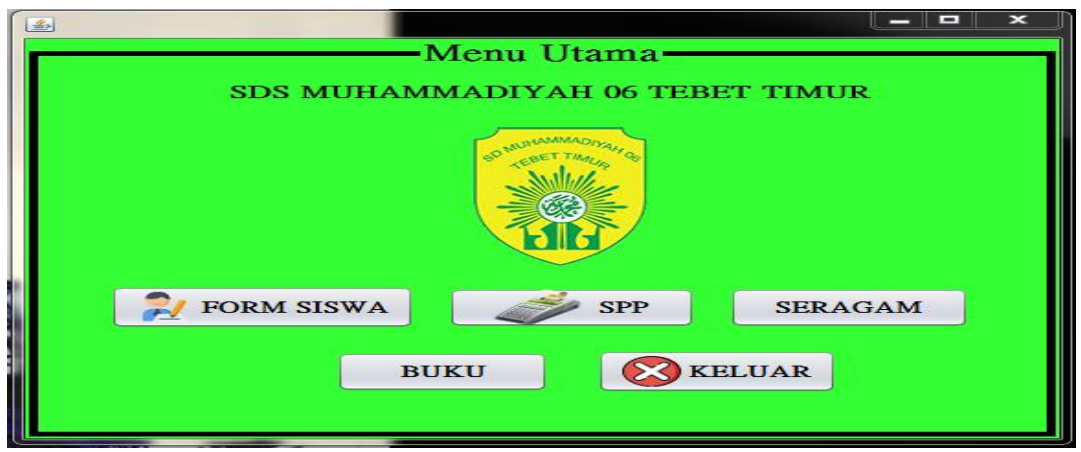

Gambar 5. Tampilan Menu Utama

Layar di atas adalah tampilan form menu utama yang berisikan menu form siswa, siswa, seragam, dan buku. 


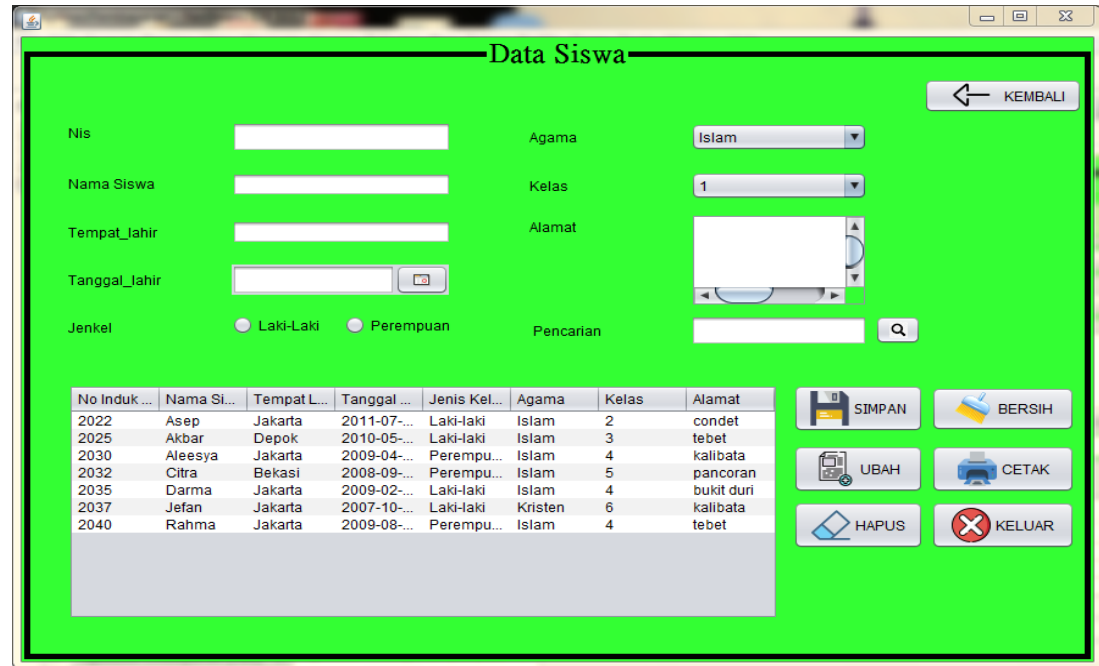

Gambar 6. Tampilan Data Siswa

Layar di atas adalah tampilan form input data siswa yang berisi nis, nama siswa, tempat lahir, tanggal lahir, jenis kelamin, agama, kelas, alamat, serta fitur pencarian.

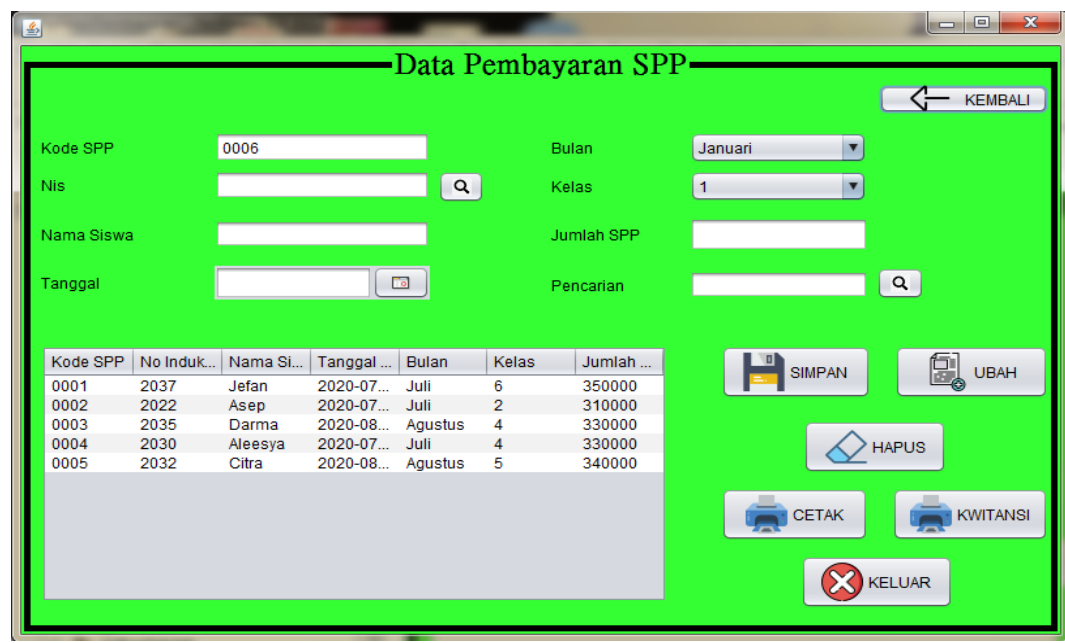

Gambar 7. Tampilan Data Pembayaran SPP

Layar di atas adalah tampilan form input data spp yang berisi kode spp, nis, nama siswa, tanggal, bulan, kelas, jumlah spp, dan fitur pencarian.

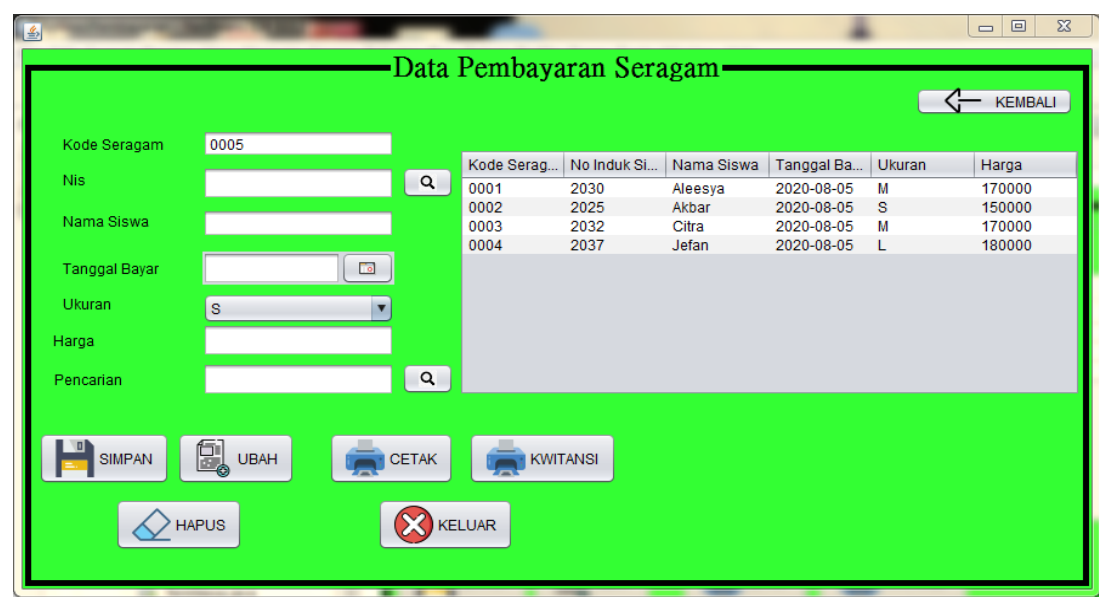

Gambar 8. Tampilan Data Pembayaran Seragam

Layar di atas adalah tampilan form input data pembayaran seragam yang berisi kode seragam, nis, nama siswa, tanggal bayar, ukuran, harga, dan fitur pencarian. 


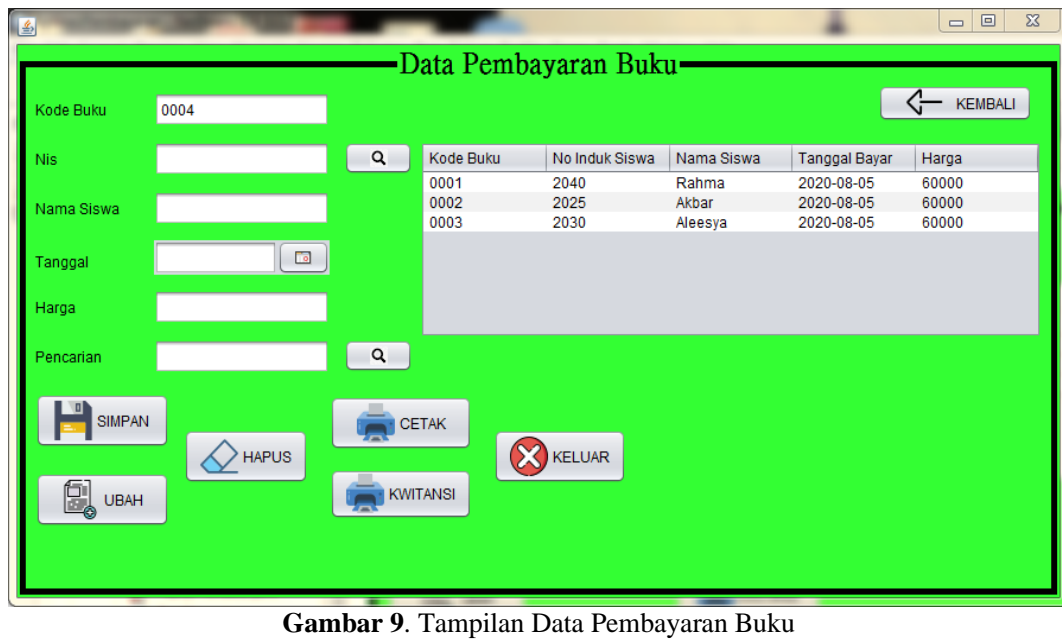

Layar di atas adalah tampilan form input data pembayaran buku yang berisi, kode buku, nis, nama siswa, tanggal, harga, dan fitur pencarian.

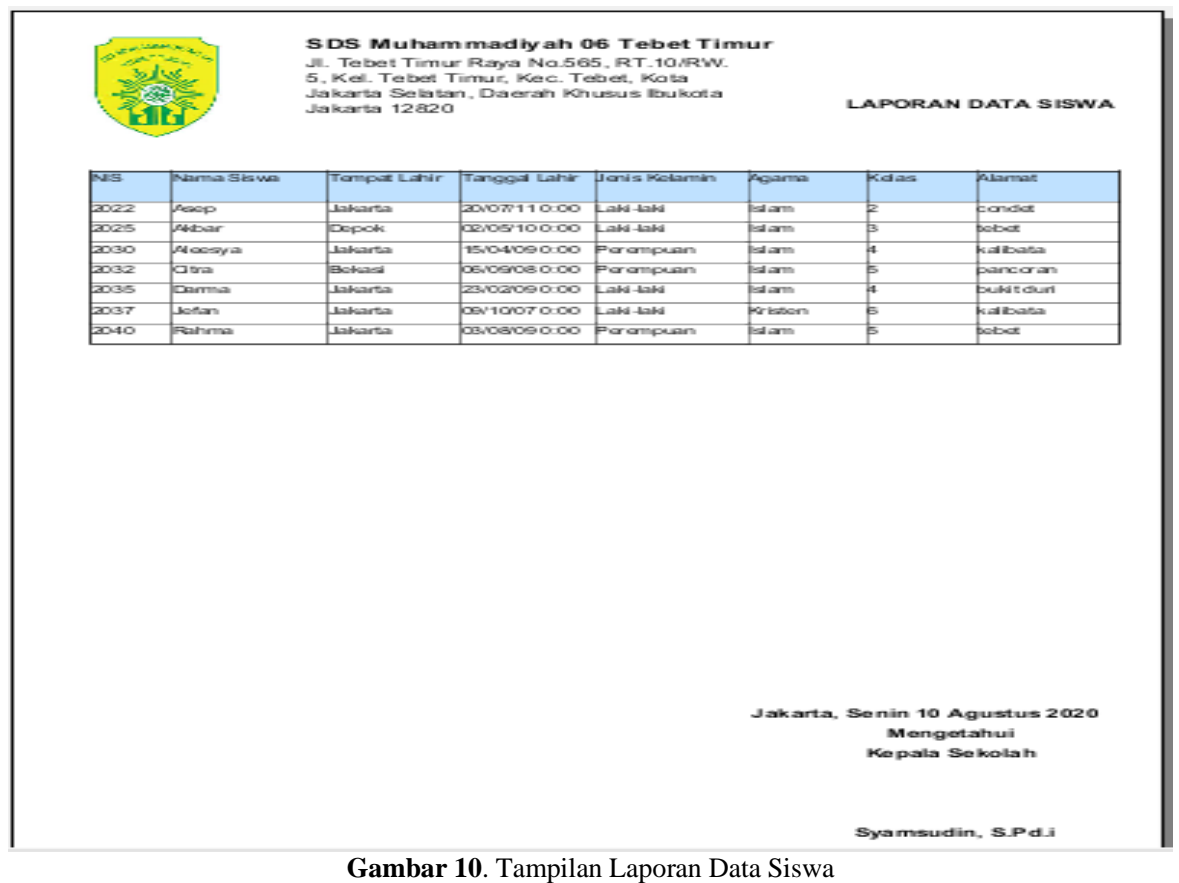

Layar di atas adalah tampilan laporan data siswa yang berisi nis, nama siswa, tempat lahir, tanggal lahir, jenis kelamin, agama, kelas, dan alamat.

\section{SIMPULAN}

Berdasarkan analisa yang telah dilakukan peneliti, maka Sistem Informasi Administrasi pada SDS Muhammadiyah 06 Tebet Timur yang dirancang peneliti dapat diterapkan dan merupakan salah satu solusi yang tepat bagi sekolah ini, sehingga dapat diambil simpulan yaitu sistem informasi administrasi pembayaran yang selama ini masih menggunakan proses pembayaran secara konvensional kini menjadi secara komputerisasi karena data-data tersebut tersimpan di dalam database. Selain itu juga untuk menghindari terjadinya duplikasi data kesalahan input serta proses pembuatan laporan tidak memerlukan waktu yang sangat lama.

\section{DAFTAR PUSTAKA}

Anastasia, D., \& Lilis, S. (2011). Sistem Informasi Akuntansi. Yogyakarta: Andi Offset.

Dewi, I. C. (2011). Pengantar Ilmu Administrasi. Jakarta: PT Prestasi Pustakaraya.

Handayani, E. R. (2015). Sistem Informasi Pengolahan Data Pembayaran Siswa Terkomputerisasi pada Bimbingan Belajar dan Konseling Galileo Institute. Jurnal Perancangan, 12(2), Hal: 49. 
Hanif, M. (2016). SISTEM INFORMASI ADMINISTRASI PEMBAYARAN PADA SDIT AL AKHYAR KUDUS.Skripsi. Kudus: UMK.

Hasibuan, M. S. P. (2010). Manajemen Sumber Daya Manusia. Jakarta: PT BumiAksara.

Hutahaean, J. (2015). Konsep Sistem Informasi. Yogyakarta: Deepublish.

Komariah, A., \& Triatna, C. (2010). Visionary Leadership Menuju Sekolah Efektif. Jakarta: Bumi Aksara.

Mulyadi. (2016). Sistem Informasi Akutansi. Jakarta: Salemba Empat.

Prabowo, D. A. (2015). RANCANG BANGUN SISTEM ADMINISTRASI PEMBAYARAN SEKOLAH MULTI USER BERBASIS WEB DI SMA NEGERI 1 TEMANGGUNG. Skripsi. Semarang: UNNES.

Romney, M. B., \& Steinbart, P. J. (2015). Sistem Informasi Akutansi. Jakarta: Salemba Empat.

Sukamto, R. A., \& Shalahuddin, M. (2013). Rekayasa Perangkat Lunak Terstruktur dan Berorientasi Objek. Bandung: Informatika, 3 . 